\title{
O 'Espelho dos Santos': analogias da Virgem Maria nos sermões de São Vicente Ferrer (1350-1419)
}

\author{
The 'Saint's Mirror': analogies of the Virgin Mary in the sermons of \\ Saint Vincent Ferrer (1350-1419
}

\author{
Gustavo Cambraia Franco \\ gustavo@gustavocambraia.com \\ Universitat d'Alacant
}

Resumo: Este artigo tem por objetivo apresentar um estudo sobre a exegese biblica e doutrinária que o frei valenciano tardo-medieval São Vicente Ferrer faz sobre o tema da mariologia. Baseado no caudal da multissecular tradição teológica e literária patrístico-escolástica, na vertente do pensamento analógico e em uma cosmovisão especular e simbólica, o pregador apresenta em seus sermões uma extensa série de analogias, metáforas, alegorias e tipologias biblicas mediante as quais enaltece a figura da Virgem Maria, e define seu significado como a personagem sagrada universal de devoção na Idade Média.

Palavras-chave: São Vicente Ferrer, mariologia, pensamento analógico, exegese bỉlica medieval

Abstract: This article aims to present a study on the biblical and doctrinal exegesis that late medieval Valencian Dominican friar Saint Vincent Ferrer does on the subject of mariology. Based on the flow of the multisecular theological and literary patristic-scholastic tradition, on the strand of analogical thought and on a specular and symbolic worldview, the preacher presents in his sermons an extensive series of analogies, metaphors, allegories and biblical typologies by which he exalts the figure of the Virgin Mary, and defines its meaning as icon and universal hagiographic model of the Middle Ages.

Keywords: Saint Vincent Ferrer, mariology, analogical thinking, medieval biblical exegesis 


\section{Gustavo Cambraia Franco. O 'Espelho dos Santos': analogias da Virgem Maria nos sermões de São Vicente Ferrer (1350-1419)}

\section{Introdução}

São Vicente Ferrer (1350-1419), padre e frei dominicano valenciano do período medieval outonal, é considerado um dos maiores pregadores populares da história da Igreja Católica ocidental, ícone e modelo hagiográfico, exitoso reformador dos costumes e homem de eminente importância e estatura na política europeia, eclesiástica e civil, entre finais do século XV e início do século XV. ${ }^{1}$ A miríade de sua produção literário-teológica em forma de sermões litúrgicos, revela, ainda, uma outra faceta do santo maestro, qual seja, a de um intelectual refinado, dotado de uma profunda capacidade especulativa, teológica, doutrinal e literária. O domínio da ciência e do conhecimento teológico de seu tempo se mostra, de maneira muito eficaz, em sua mariologia e nos sermões que se dispõe a tratar sobre o tema da Virgem Maria.

A partir do século XI, com a renovação intelectual e cultural, e com o movimento de profundas reformas que desabrochou na Igreja a partir do papado de Gregório VII, o Ocidente testemunhou o crescimento rápido e instantâneo de inúmeras formas de piedade, devoção e culto à figura da Virgem Maria. Embasados na perspectiva teológica de orações e tradições precedentes, foi na Baixa Idade Média, contudo, que se passou a considerar de maneira central a exemplaridade de Maria, seu papel na obra da salvação e sua importância na vida cristã. Reflexos de um contexto de contemplação, exaltação, homenagens cultos à figura e às virtudes de Maria, os sermões de São Vicente Ferrer são, também, obras robustecidas por uma profunda piedade e por sólidas doutrinas mariológicas. A piedade mariana de São Vicente Ferrer se manifesta em muitos detalhes de seus sermões, e temas teológicos relacionados com a figura da Virgem Maria encontramse distribuídos em praticamente todos os sermões vicentinos, com propósitos diversos. Há inúmeros sermões dedicados integralmente a temas marianos, sobretudo aqueles pregados em dias específicos de festas e celebrações oferecidas em memória da Virgem, como, por exemplo, da Imaculada Conceição, da Apresentação da Virgem Maria no Templo, da Anunciação, da Purificaşão e da Assunção. Em outros sermões pregados durante o ciclo litúrgico, a colher referências de passagens e contextos evangélicos diversos, São Vicente Ferrer não deixa de inserir reflexões, meditações e doutrinas sobre a figura de Maria, sobretudo no caso de grandes festas como o Natal, a Páscoa e Pentecostes. Uma compreensão e vislumbre mais abrangentes dos conteúdos, ideias e temas marianos de seus sermões exigem um esboço prévio sobre as fontes e os métodos utilizados pelo pregador para a elaboração dos sermões.

1 Como referências para um estudo contextual e biográfico de São Vicente Ferrer, e análise histórico-cultural de seus sermões, ver Martines Peres (2012: 582-597); Martínez Romero(1992: 9-46 e 1992b); Ysern i Lagarda (2003: 73-102); Esponera Cerdán (2006); Enric Rubio (2007: 133-144); e, ainda, o extenso trabalho de Perarnau i Espelt (1999: 09-62). 
Gustavo Cambraia Franco. O 'Espelho dos Santos': analogias da Virgem Maria nos sermões de São Vicente Ferrer (1350-1419)

\section{As fontes e os métodos de São Vicente Ferrer}

A renovação das letras, desde o século XII, e o desenvolvimento do método escolástico implicaram novas necessidades de aprendizado e novas concepções sobre o ensino, a leitura e as formas de argumentação. Os instrumentos do trabalho intelectual se diversificaram seguindo uma tendência maior de racionalização na elaboração de materiais e obras. Diversos instrumentos exegéticos enriqueceram os modos de investigação das Escrituras e facilitaram o acesso a um conhecimento que havia se ramificado e se tornado enciclopédico. Os comentaristas passaram a ter a sua disposição glosas, sumas, compêndios e florilégios com extratos de citações bíblicas e referências de autoridades como, por exemplo, a Glosa Ordinaria, manuais de sentenças patrísticas, manuais jurídicos, fragmentos de obras filosóficas antigas, sobretudo aristotélicas, etc. (Hamesse 2004: 190 ss). Novos métodos de pesquisa passaram a ser aplicados ao estudo dos textos e caminhavam vis-a-vis com o trabalho exegético. Coletâneas de concordâncias ${ }^{2}$ reais e verbais, de correções e de distinctiones $^{3}$ e o novo método de divisão sistemática do texto bíblico em capítulos e parágrafos numerados, tudo isso permitiu um acesso mais rápido ao texto e forneceu um sistema claro de referências aos comentaristas e sermonistas que, agora, podiam ter um domínio facilitado e mais abrangente do texto sagrado. Entre os séculos XIV e XV, período de atividade missionária de Vicente Ferrer como pregador itinerante, os sermões já haviam se tornado peças teológicas, literárias e retóricas de composição e estrutura muito complexas. Os chamados sermões temáticos, como no caso de São Vicente, apresentavam-se como verdadeiras teses, provadas por meio de uma cadeia sequencial e lógica de argumentos desenvolvidos em torno de uma série de citações e autoridades bíblicas e extra-bíblicas.

A estrutura e os conteúdos dos sermões de São Vicente Ferrer expressam a forma orgânica de seu pensamento, bem como sua lucidez e erudição teológica. De uma forma geral, seus sermões são elaborados com base nos manuais das Artes Praedicandi que abundavam em seu tempo, e as opiniões se dividem acerca de qual material principal seria usado pessoalmente pelo pregador. De acordo com seu próprio testemunho, e alinhado com a tradição dominicana, parece que sua base era o manual de pregação de Tomás Wasley $(† 1349)^{4}$, ou, ainda, o manual do franciscano Francisco Eiximenis (c.

2 As Concordantia medievais ordenavam alfabeticamente todas as palavras da Bíblia e, para cada entrada, mencionam os diferentes lugares (livro, capítulo, versículo) nos quais aparecem. A ferramenta facilitava a consulta do pregador a obras extensas e possibilitava uma maior rapidez, exaustividade e eficácia (Sánchez Sánchez 1999: 59-60).

3 As Distinctiones são textos-ferramentas de consulta bíblica utilizados para servir de ajuda à composição de sermões. Elas distinguem (daí seu nome) os quatro sentidos ou níveis de significado de um termo das Escrituras (literal, alegórico, moral e tropológico) e acrescenta a cada um deles uma citação bíblica paralela. Desde o século XII, as Distinctiones se desenvolveram como gênero literário próprio, através da compilação sistemática de referências e, com o tempo, se tornaram verdadeiros dicionários (Dictionarius) temáticos e linguísticos. Sánchez Sánchez (1999: 127) ressalta que la «dificuldade para identificar el influjo (el modelo supuestamente seguido por un autor) de unas Distinctiones es particularmente grande en un autor como Vicente Ferrer, cuya poderosa imaginación le lleva a crear desarollos próprios que desdibujan o, por mejor decir, camuflan uma estrutura de partida que seguramente sacó de su mollera, pero que pudo haber tomado de otro sitio».

4 Este é o parecer de Robles Sierra e Esponera Cerdán (s/d: 4). Martínez Romero (1993: 25), por sua vez, enxerga

SCRIPTA, Revista internacional de literatura i cultura medieval i moderna, núm. 10 / desembre 2017 / pp. 26-48 ISSN: 2340 - 4841 doi:10.7203/SCRIPTA.10.11073 
1330-1409), contemporâneo de Ferrer. Nosso sermonista se baseava sempre no ciclo litúrgico e no calendário festivo da Igreja, cujo ponto de partida era a leitura bíblica da Missa do dia, de acordo com os livros litúrgicos da ordem dominicana. As leituras podiam ser dos Evangelhos, das cartas dos Apóstolos, do livro de Atos e do Apocalipse, ou, ainda, trechos do Antigo Testamento, embora estes fossem menos frequentemente utilizados como temas. O pregador utilizava Lecionários e Hinos litúrgicos, prefácios, orações, antífonas e demais elementos do Breviário e do Missal pertencentes à liturgia própria dos dominicanos. As leituras do Breviário consistiam em extratos hagiográficos e homilias patrísticas relacionadas ao evangelho do dia. Em seus sermões abundam relatos hagiográficos, retirados, sobretudo, do Martirológio Romano, da Legenda Aurea de Tiago de Voragine (c. 1228-1298), do Speculum maius de Vicente de Beauvais (c. 1190-1264) ou de coletâneas de exempla. Utilizava, em larga medida, também, as Glosas Ordinarias e Interlineares, a obra de Hugo de Saint-Cher (c. 1200-1263) e do comentarista Nicolau de Lira (c. 1270-1349), ${ }^{6}$ bem como a famosa obra Historia Scholastica de Pedro Comestor (c. 1110-1179). ${ }^{7}$

Os métodos utilizados por São Vicente Ferrer para a confecção de seus sermões pautam-se nos princípios da analogia bíblica e da analogia fidei e, sobretudo, no método universal medieval dos quatro sentidos da Escritura. A exegese ferreriana se alimenta pela concordância entre diversos níveis de autoridades. A unidade da autoria divina do Antigo e do Novo Testamento legitima a leitura e interpretação de passagens obscuras e menos claras contidas em um livro a partir de sua comparação com textos de outro livro. A ideia da transcendência dos mistérios revelados e a concepção unitiva da verdade revelada permite, assim, que distintos textos bíblicos se esclareçam e se iluminem reciprocamente. O confronto de autoridades, como regra que determina a interpretação de um autor à luz de textos de outros autores e passagens paralelas, é legitimado pela noção de que a revelação possui um caráter progressivo, que concebe os eventos, ensinamentos e revelações do Antigo Testamento como gérmens e figuras da revelação plena contida na Nova Aliança (Correa 1979: 37-38), nos atos e palavras de Cristo e de seus Apóstolos, o que nos estudos hermenêuticos costuma-se chamar de tipologia das Escrituras.

Na concepção medieval, o universo inteiro era concebido como uma rede de significados, na qual tudo o que existe no plano material e ideal consistia em imagens, reflexos e espelhos cujos fragmentos remetiam à unidade do ser do Modelo primeiro e eterno de Deus. Os livros bíblicos também eram especulares, entendidos como espelho de um conhecimento superior. O que autores como Santo Agostinho (c. 354-430) e Santo Isidoro de Sevilha (c. 560-636) entendiam pela Concordantia Veteris et Novi Testamenti era justamente uma ideia tipicamente analógica, ou seja, a de que existe uma unidade fundamental e mística entre todos os livros sagrados. Compreendia-se que todos os

na estrutura do sermão vicentino a influência da obra de Francisco Eiximenis.

5 Citamos a edição em língua portuguesa (Jacopo de Varazze 2003).

6 Ver Schmitt (1982: 291-292).

7 Seguimos aqui o breve resumo das fontes vicentinas de Perarnau i Espelt (1987: 7). 
livros da Bíblia eram frutos da inspiração de um único autor, que fez das Escrituras o "espelho da salvação humana" (speculum humanae salvationis), conforme diz Santo Agostinho (1861-1864, v. 34, c. 889) e que, portanto, deve ser observado nelas um fator de continuidade e preenchimento. $\mathrm{O}$ Antigo Testamento é um espelho do Novo, cujos mistérios eram uma preparação e antecipação do advento cristão. No espaço literário bíblico e no conteúdo de seus relatos, eventos e personagens, os medievais encontravam, interna corporis, uma série de correlações e correspondências históricas, proféticas e espirituais. Uma vez que as verdades da revelação divina são expressadas sobremaneira por analogias, o trabalho do exegeta era sempre o de aproximar narrativas e episódios distantes da Bíblia para que se pudesse exaurir deles um sentido único de fé.

Tal como os comentaristas de seu tempo, São Vicente Ferrer explica a doutrina teológica por meio de motivos bíblicos, o que o leva a comentar um versículo recorrendo sucessivamente a outras passagens e textos da escritura. ${ }^{8}$ Cada ratione ou argumento é seguido de uma citação bíblica, amparada por outras que a confirmam ou têm o mesmo sentido, em um encadeamento harmonizado de autoridades. O princípio adotado é o de esclarecer a Bíblia pela própria Bíblia, e com o auxílio de uma série de autores consagrados. A analogia da fé e o método exegético de articulação das citações e argumentos, como aplicado por Correa para o caso de Santo Tomás de Aquino, pode, também, ser aos sermões temáticos de São Vicente Ferrer. As referências de autoridades se distribuem da seguinte forma: quanto à analogia bíblica, (1) pela interpretação do Antigo Testamento à luz do Novo, (2) pela interpretação de um determinado autor sagrado por outros textos do mesmo autor e (3) pela interpretação do texto de um autor através de passagens de outro autor; quanto à analogia da fé católica, (1) pela exclusão e refutação de interpretações heréticas, (2) pelo recurso aos Santos Padres e (3) pela interpretação à luz da doutrina da Igreja (ou da Regula Theologiae) e dos Artigos da Fé.

O método por excelência de interpretação das Escrituras utilizado por São Vicente Ferrer é aquele que tradicionalmente prevaleceu durante toda a Idade Média, o qual reflete e reforça, de maneira acentuada, a mentalidade simbólica, analógica e especular de seus sermões. A exegese dos quatro sentidos da Escritura determinava que passagens e relatos da Bíblia comportam dois níveis de interpretação: o sentido imediato e claro, determinado por sua letra, pela narrativa e pela história factual, o qual denominaram de sentido literal/ histórico; e um conjunto de sentidos ou significados mais elevados, que apontam e estão dirigidos para realidades que extrapolam a letra do texto, denominados de sentidos espirituais, os quais, por sua vez, englobam três sentidos: alegórico, moral/ tropológico e anagógico. O sentido alegórico contém o significado de fé do texto sacro, aquilo que deve ser crido, e que pode se referir a Cristo, à Igreja, aos sacramentos e mesmo aos demais eventos, coisas e personagens do Novo Testamento que haviam sido prefigurados no Antigo Testamento. O sentido moral/ tropológico determina, por sua vez, aspectos da vida espiritual e moral do homem, aquilo que deve praticar e como se comportar. A anagogia representa uma mudança de direção para

8 O princípio segundo o qual a Bíblia se esclarece pela Bíblia é antigo e propriamente exegético. Os rabinos judaicos procuravam estabelecer o sentido incerto de uma palavra ou de um texto por meio da comparação com o sentido que ela tinha em outro texto ou livro. Esta prática permanece ainda em vigor na exegese atual (Correa 1979: 36). 


\section{Gustavo Cambraia Franco. O 'Espelho dos Santos': analogias da Virgem Maria nos sermões de São Vicente Ferrer (1350-1419)}

o futuro, para a contemplação das realidades superiores e espirituais. O sentido anagógico se traduz como uma "escalada", subida" e "ascensão" para o alto, uma compreensão mística direcionada ao futuro." Contemplação da vida a ser fruída após o final dos tempos, naquele que os medievais chamavam de "Céu empíreo", lugar espiritual da companhia e comunhão de Deus, dos santos e dos anjos. A interpretação anagógica direciona o olhar para o Paraíso e para o gozo da beatitude eterna na visão íntima e direta de Deus. Todos estes sentidos se encontram presentes na exegese de temas marianos de São Vicente Ferrer, que os intercala na exposição, ora enfatizando um ou outro. Fiel à uma tradição exegética secular ${ }^{10}$, o pregador considerava a quadriga mundi ou ordine quadrato como o único e verdadeiro método de entendimento e exposição do texto sacro, em uma época na qual novos métodos e abordagens das Escrituras começavam a ser utilizados, impulsionados pelo desabrochar do bumanismo, do resgate de elementos do classicismo e do espírito crítico que o acompanhava.

Os sermões de São Vicente Ferrer, típico exemplo do sermão temático medieval, são obras literárias do gênero especular, baseadas no método do pensamento analógico, porque neles se manifesta, de maneira abrangente, o jogo especular entre o mundo espiritual e o mundo sensível e natural, construído sobre as bases da metáfora, da expressão didática do simbolismo e da exegese alegórica e moral das Escrituras. Seu conteúdo primordial e básico são temas bíblicos, nos quais a própria Bíblia é concebida como um "espelho" do livro aberto do mundo. A visão catóptrica e a linguagem hermenêutica simbólica e figural da Bíblia, da natureza e do mundo criado encontram um terreno fértil nas especulações dos sermões vicentinos. As compilações de exempla aparecem como um desses gênero de interposição simbólica, usado como recurso de memorização e aprendizado tendo em conta a familiaridade das imagens, concretas ou ilustrativas, do cotidiano, por meio das quais se ensinava de um modo mais fácil e atrativo. O uso de metáforas, alegorias e imagens, concomitantemente desenhadas e decifradas diante do público, tinha como propósito elucidar verdades espirituais por meio da comunicação de ideias que se baseavam na realidade, o que tornava mais eficaz o discurso e instigava a imaginação, a sensibilidade e a devoção do ouvinte ou do leitor (Nuet Blanch 2000-2001: 59).

\footnotetext{
9 Significado expressado, de acordo com De Lubac (2002: 183), pela própria etimologia do termo grego anagoge (ana, que significa "alto", "superior" e agoge, isto é, "levar", "conduzir").

10 Sobre a tradição exegética medieval dos quatro sentidos, além da obra seminal de De Lubac, ver o capítulo de nossa tese doutoral na qual apresentamos um esboço geral do tema entre os principais autores patrísticos e escolásticos (Franco 2017: 215-230). Um dos mais famosos autores a teorizar sobre o método dos quatro sentidos, e de quem São Vicente Ferrer faz memória, foi Hugo de São Vítor (c. 1096-1141). Seu tratado intitulado Didascalicon divide e classifica, sistematicamente, as formas de conhecimento. Neste trabalho, e também em seu opúsculo introdutório a suas obras exegéticas, o autor desenvolve o entendimento dos quatro sentidos das Escrituras, distinguindo entre o significado literal (bistoria) e o profundo significado para além da letra (alegoria, tropologia e anagogia). Cf. (Hugo de São Vítor 2001: 235; e 1879: v. 175, c. 09-28).
} 
Gustavo Cambraia Franco. O 'Espelho dos Santos': analogias da Virgem Maria nos sermões de São Vicente Ferrer (1350-1419)

\section{Culto e devoção a Virgem Maria na Baixa Idade Média}

O culto à Virgem Maria na Idade Média cresceu movido pelas mesmas razões que cresceu o culto dos demais santos e a devoção à humanidade de Cristo, ou seja, o desejo dos medievais de contarem com intercessores e mediadores entre os homens e a majestade temível de Deus, pois não podia haver ninguém melhor que a própria mãe do Salvador para interceder junto ao Filho. Nos mosteiros, multidões se agregavam para assistir as solenidades e festejos dedicados à Virgem. A pregação mariana nasce no ambiente monástico, fruto da meditação e da lectio divina sobre textos bíblicos e leituras alegóricas relacionadas à figura de Maria (Boaga 1998: p. 179). A reflexão teológica sobre Maria encontrou fecundidade sobretudo entre os cistercienses. Os sermões e meditações de São Bernardo de Claraval (c. 1090-1153) ${ }^{11}$, como presentes em seu Comentário ao Cântico dos Cânticos, ofereceram à literatura e a lírica novas imagens e expressões vivas dessa intensa corrente de amor, devoção e culto à Mãe de Deus. O que estava criado, a partir de então, era um programa de espiritualidade mariana sustentado por três pilares: honrar a Mãe de Deus; pregá-la com fidúcia e confiança; imitar as suas virtudes. Em verdade, todas as grandes figuras espirituais dos séculos finais da Idade Média trabalharam para reforçar e difundir a corrente de devoção mariana, como São Boaventura (c. 1221-1274) ${ }^{12}$, Santo Anselmo (c. 1033-1109) ${ }^{13}$, Hugo de São Vítor, o teólogo e pregador franciscano Conrado da Saxônia ( $†$ 1279), autor do Speculum seu salutatio beatae Mariae Virginis (Espelho ou saudação à Santíssima Virgem Maria), um tratado sobre a Virgem que teve ampla difusão no medievo, além do teólogo Ricardo de Saint-Laurent († 1250), compositor do De laudibus beatae Mariae Virginis, um longo Mariale ou louvor à Virgem Maria, editada em 1473, e de São Domingos de Gusmão (c. 1170-1221), fundador da Ordem dominicana, Ordem essa mariana por vocação (Bedouelle 1987: 295-297; Jedin 1986: 300).

O fenômeno do culto mariano, considerado, então, uma das maiores manifestações da fé cristã, consignou-se em diversos tipos de homenagens, na hagiografia e literatura, na liturgia e opúsculos devocionais, nas artes e na pregação. Catedrais foram construídas e consagradas em honra do nome de Maria. Em torno da Notre-Dame de Paris, outras sete igrejas são desenhadas e dispostas como as pétalas de uma flor, e a figura da Virgem é destacada nas pinturas dos vitrais, nas esculturas dos pórticos e nos tímpanos das igrejas. Antífonas e hinos são compostos, como a Salve Regina, a Ave Regina coelorum, Regina Coeli e Alma Redemptoris Mater, e cantadas em procissões, ofícios divinos e como cânticos de batalha nas Cruzadas. Nesse mesmo período, difunde-se entre os cistercienses o costume, proveniente dos ambientes de cavalaria e do amor cortês, de invocá-la com o nome de Nossa Senhora (Daniel-Rops 1993: pp. 63-64).

11 Ver Costa (2011: 125-140; 2010: 223-238 e 2009: 97-105).

12 Sobre a vida e obra de Boaventura, ver (Bougerol 1988; e Corvino 2006).

13 Ver o verbete de Schmitt(1988: 495-497).

SCRIPTA, Revista internacional de literatura i cultura medieval i moderna, núm. 10 / desembre 2017 / pp. 26-48 ISSN: 2340 - 4841 doi:10.7203/SCRIPTA.10.11073 
O culto à Maria acompanha, portanto, a ascensão poderosa e universal do Amor e do culto à Mulher idealizada (Rougemont 1988: p. 95). A partir do século XII, as relações entre o devoto e Maria, sejam as de ordem contemplativa, seja na prática da pregação ou da imitatio, refletem um espelho de tipologias. Maria é a Mãe espiritual, a Patrona e Senhora, a Mestra e Guia, o Modelo de fé. Para São Vicente Ferrer, Maria é a jovem Virgem Santíssima, o aposento do Espírito Santo, a Porta do Paraíso e a Rainha do Céu. ${ }^{14}$ A piedade mariana se manifesta, ainda, através de diversas fórmulas de orações que acompanham o cotidiano dos medievais, entre elas a Ave-Maria, o Angelus e o Rosário. O convite a orar cotidianamente à Virgem para a obtenção de favores e graças espirituais e materiais foi propagado mediante inúmeros exemplo hagiográficos, como a da Legenda Aurea de Tiago de Voragine, na poesia e literatura, sobretudo a Divina Comédia de Dante Alighieri (c. 1265-1321), na pregação popular, e em prescrições legislativas e canônicas conciliares, nas quais se requeria aos clérigos exortarem o povo à recitação da "saudação à Virgem Santa". No âmbito litúrgico, a figura de Maria é quase onipresente e alusões e referências ao seu papel no plano da salvação e à sua figura materna e intercessora encontramse espalhadas em quase todas as partes do rito da Missa e do Cânon Romano.

Nas representações sacras, envolvidas pela atmosfera do canto gregoriano, nasce e se desenvolve, do século XIII ao XV, a chamada Lauda, uma forma popular de composição e recitação formada por textos rimados em língua popular, muito usado nas Confrarias devocionais. Os temas de devoção são variados, como, por exemplo, a devoção às Sete Dores de Maria, que se desenvolveu a partir do século XII através dos escritos de São Bernardo e Amadeo de Lausana (c. 1110-1159) (Comte 1877), propagado pelos cistercienses e pelos Servos de Maria. A devoção adquire formas religiosas e artísticas variadas, e se encontra em afrescos, miniaturas, esculturas e composições literárias, como o célebre conjunto de versos rimados do Stabat Mater, composto pelo poeta e místico italiano Jacopone da Todi $(1236-1306)^{15}$, que teve enorme sucesso em toda a Europa (Maggioni 1998, p. 63 ss).

No plano literário hispânico e catalão, seguiu-se um movimento de exaltação poética a Virgem Maria presente, por exemplo, no Llibre d'Ave Maria de Ramon Llull (c. 1232-1316), cuja obra narra a história de um cavaleiro que, convertido, passou a devotar sua vida ao serviço da Virgem. O culto intensificou-se, ainda, pelas coleções marianas das Cantigas de Santa Maria de Afonso X, o Sábio (c. 1221-1284), dos Milagros de Nuestra Señora, de Gonzalo de Berceo e da obra catalã de Lérida, Miracles de la Verge Maria. As expressões do cancioneiro popular e a cristianização da ética do amor cortês permitiram que o culto a Maria se difundisse, assim, por meio da poesia trovadoresca. A figura de Maria, dama casta e Senhora celestial, mulher idealizada e supereminente em graça e beleza por sobre todas as criaturas, se tornou objeto de exaltação e serviço amoroso de cavaleiros e clérigos devotos (Ávila 2016: 14 e 16). No universo litúrgico e artístico do gótico hispânico e catalão, no qual a figura da Virgem Maria é um topos recorrente, os principais temas iconográficos

14 «[... puellam Virginem Sanctissimam, quae esset Mater Filii sui, Camera Spiritus Sancti, Porta Paradisi, Regina Coeli.» (Sancti Vicentii Ferrarii 1695: 21).

15 Ver, ainda, (Suitner 1999; e Canettieri 2001). 
salientam o status de Maria na ordem criada, sua supereminência sobre as demais mulheres, sua supereminência sobre as demais criaturas, a incluir os anjos e os santos, seu papel de intercessora da humanidade junto a Cristo, e seu papel único e exaltado como a via e caminho de acesso à salvação eterna concedida por seu Filho àqueles que na terra foram devotos da mãe (Salvador González 2013: 15).

A devoção mariana já havia sido difundida e estabelecida na Península Ibérica desde o século XII. Como sintetiza Rodríguez (2014: 81-82), ao tratar da Ordem dominicana, à qual São Vicente Ferrer pertencia, vemos que os frades alvinegros consagram à Maria uma porção substancial e essencial de sua vida litúrgica, cerimonial e devocional. Nos ofícios dos conventos, as matinas são dedicadas a Virgem, assim como nos principais atos de piedade e oração. Os dominicanos são marianos por vocação e inspiração. A presença de Maria era constante e apoiava a Ordem em todas as circunstâncias da vida diária, nas orações, nos trabalhos, no estudo, nas pregações, nos sermões e na assistência aos enfermos e como viático dos moribundos, nas missões e nos capítulos. O culto prestado à Virgem veio, ainda, a ganhar um novo e renovado impulso com a recitação dos mistérios do Rosário. A história do Rosário é pouco conhecida, devido sobretudo à falta de documentação e fontes. Promovido por São Domingos de Gusmão, fundador da Ordem dominicana, o Santo Rosário era usado por pregadores como arma espiritual no combate contra os hereges cátaros que negavam a maternidade divina de Maria, e quem o popularizou definitivamente foi o dominicano Alano de Rupe (1428-1475). No entanto, foi Domingos, de fato, quem deu ao Rosário uma finalidade evangelizadora, e foi a ordem dominicana que converteu esta devoção inicialmente particular em uma oração eclesial universal A tradição desta prática de oração e meditação, que permanece viva na Igreja nos tempos atuais, demonstra como a sua prática incessante impulsionou a fundação de inúmeras instituições, confrarias e irmandades populares, constituídas de membros seculares.

\section{Analogias da Virgem Maria nos sermões de São Vicente Ferrer}

Existem diversos sermões de São Vicente Ferrer consagrados inteiramente à Virgem Maria, e na introdução de cada sermão, que geralmente apresenta um formato padrão, o pregador menciona o tema do sermão, constituído por uma passagem bíblica e um breve esquema das matérias a serem tratadas ao largo do texto. São Vicente insere uma saudação à Virgem Maria e um convite preliminar à oração da Ave-Maria. Chegou-se a aventar a hipótese de que o costume dessa prática tenha sido primeiramente introduzido na pregação ocidental pelo próprio São Vicente Ferrer. O costume da saudação e da oração mariana, sempre habituais na introdução do sermão, é significativo do modo como a utilidade prática, as razões e o desenvolvimento de tudo aquilo que será abordado no sermão estão solidamente fundamentadas, em primeiro lugar, no sentimento e na piedade verso à figura de Maria. O fato de que todos os seus escritos contenham uma saudação à Virgem logo no começo e no cabeçalho do texto demonstra que o santo possuía um espírito eminentemente 


\section{Gustavo Cambraia Franco. O 'Espelho dos Santos': analogias da Virgem Maria nos sermões de São Vicente Ferrer (1350-1419)}

mariano, que o levava a encomendar constantemente seus atos e palavras à presidência e regência espiritual daquela que, para o santo, era a Mãe de Deus, sua Senhora. O costume da saudação revela a profunda piedade, veneração e confiança do santo de que, sob os auspícios e apoio da Virgem Maria, o sermão pregado seria eficaz, suas palavras bem pronunciadas e seus ensinamentos bem compreendidos e praticados pelos fiéis (Sauras 1972: 43-69).

No que tange a sua teologia e exegese, pode-se resumir o esquema mariológico vicentino a partir de quatro tópicos fundamentais de pregação: sua maternidade divina, sua concepção imaculada, suas virtudes e os tipos e prefigurações de Maria anunciados e descritos no Antigo Testamento. A exposição de temas marianos segue, em primeiro lugar, o princípio da analogia e da exegese alegórica da Bíblia. Algumas metáforas se destacam no quadro geral da mariologia vicentina. Em um sermão da Vigília de Natal, por exemplo, São Vicente Ferrer apresenta a analogia entre Maria e o velo de lã, a partir da interpretação do significado místico das palavras de Davi: Descendet sicut pluvia in vellus et sicut stillicidia stilantia super terram (S/71: 6). Segundo o pregador, o texto é uma profecia da concepção oculta e secreta de Cristo. A Virgem Maria é significada pelo velo de lã e pela terra fecunda, sobre a qual desce a chuva e na qual frutifica o Filho de Deus.

Et vocat Virginem Mariam, vellus: nam sicut de lana alba, sit vestimentum pro induendo, ita Christus recepit carnem, vestimentum de lana in carne pura et munda Virginis: et dicit terram: na sicut terra fructificat, ita virginalis terra Virgo Maria fructificavit Filium Dei Christum hominem; et dicit Sicut pluvia descendet in vellus, nam sicut secrete pluvial descendit in vellus lanae, quod non sentientis, ita Filius Dei secrete descendit in illo puncto denuntiationis Angeli, quod nullus scivit illud secretum, nisi Virgo et Archangelus. Patet ergo differentia inter nativitatem Christi et eius conceptionem (Sancti Vicentii Ferrarii 1693: 180).

A analogia com o texto de Davi é completada por São Vicente Ferrer com o sermão do dia seguinte, o sermão de Natal, no qual o autor apresenta a diferença entre a natureza secreta e oculta da concepção com o caráter público e manifesto do nascimento de Cristo. Para ilustrar as circunstâncias e o contexto do nascimento de Cristo, São Vicente se vale das palavras do profeta Ageu: Adbuc unum modicum est et ego commovebo coelum et terram et mare, et aridam, et movebo omnes Gentes; et veniet desideratos cunctis Gentibus (Ag 2: 8-9). A mesma terra antes fecundada pelo orvalho da encarnação de Cristo fora, com seu nascimento, comovida pela vinda daquele que era esperado pelos povos e nações.

De acordo com Ferrer (1693: 189-190), o texto sagrado diz unum modicum, pois breve foi o tempo entre a profecia de Ageu e a vinda de Cristo. Os céus abalados referem-se ao céu empíreo imóvel, onde habita os anjos, pois de acordo com Santo Tomás, quando um anjo recebe alguma revelação de Deus, logo a comunica aos demais, de modo que nada permaneça em segredo. O próprio Arcanjo Gabriel, que recebeu de Deus a revelação da Encarnação e do Nascimento de Cristo, foi o núncio que transmitiu a mensagem aos demais anjos, de maneira que todo o céu se comoveu de alegria, gozo e celebração pela reparação feita à ruína outrora causada pelos maus. A Virgem Maria é a terra virgem

SCRIPTA, Revista internacional de literatura i cultura medieval i moderna, núm. 10 / desembre 2017 / pp. 26-48 ISSN: 2340 - 4841 doi:10.7203/SCRIPTA.10.11073 


\section{Gustavo Cambraia Franco. O 'Espelho dos Santos': analogias da Virgem Maria nos sermões de São Vicente Ferrer (1350-1419)}

que fora fecundada com o fruto da vida e que se comoveu com o anúncio do anjo, conforme relata o evangelista Lucas: «E, vendo-o ela, turbou-se muito com aquelas palavras.» (Lc 1: 29).

Outra analogia acerca da maternidade divina de Maria é novamente apresentada por São Vicente Ferrer em um sermão da Páscoa, que traz como tema a passagem do Evangelho de São Lucas que diz: Tu solus peregrinus est in Ierusalem (Lc 24: 18). São Vicente utiliza o contexto do diálogo entre Cristo e os discípulos de Emaús para apresentar Jesus como um peregrino. Nosso autor formula várias analogias e comparações entre as características e detalhes das insígnias, sinais e indumentárias do peregrino com aspectos e detalhes da vida Cristo. Com efeito, uma das características de um peregrino é o tipo de hábito ou o conjunto de vestimenta que ele utiliza, formado pela esclavina, pelo bolso, pelo báculo e pelo sombreiro, cada qual a servir a um propósito durante a caminhada, como proteger-se da chuva, do sol e do frio, no caso da esclavina e do sombreiro, o bolso para carregar materiais e objetos necessários para se manter, e o báculo para apoiar-se e facilitar a caminhada.

Cada objeto descrito se relaciona com um determinado aspecto ou momento da vida de Cristo. O bolso é a alma de Cristo, na qual estão depositados os tesouros de sua divindade, sua glória, sua graça e sabedoria. O báculo significa a cruz, pois Cristo, apoiando-se na sua cruz, sustentou a fadiga dos homens e transitou pelo rio desse mundo até a pátria celeste. O objeto que merece especial atenção, por tratar diretamente da maternidade divina de Maria, é a esclavina, um tipo de capa ou cobertura de pele que protege os ombros e o corpo do peregrino, a qual, por sua vez, refere-se ao momento da Encarnação. Assim como a esclavina protege o corpo do peregrino, assim Cristo foi coberto pela carne de Maria durante sua gestação.

\footnotetext{
Per sclaviam significatur eius caro, quam Virgo Beata in utero sibi ministravit [...] Quod Beata Virgo se habuit active in praeparatione materiae, sed non in conceptione Christi [...] Quod conceptione Christi atribuitur Spiritui Sancto efficienter, licet sit a tota Trinitate et a singulis Personis. Ista sclavia primo fuit albissima, idest purissimis guttis sanguinis Beatae Virginis facta sine omni peccato, unde Christus dicit de se et de aliis, qui habent sclavias, idest corpora sua pura. Apoc. 3, 4. Ambulabunt mecum in albis, quia digni sunt. Deinde ista sclavia facta est tota rubea in cruce, quia tota ipsa fuit aspersa sanguine [...] Ultimo facta est ista sclavia tota nigra, quando remansit in Cruce mortua et livoribus plena.
}

Maria é a esclavina ou a capa do peregrino, isto é, a carne pura e alvíssima que envolveu a humanidade de Cristo e a engendrou. Ela é, portanto, Mãe de Deus e do Verbo Encarnado. Ela foi fecundada pelo Espírito Santo, por atribuição, e fecundada, de fato, por toda a Trindade e por cada uma de suas Pessoas. A explicação do mistério da Encarnação e da maternidade divina de Maria, baseada no recurso da analogia e no metaforismo da Bíblia, é recolhida, ao longo do sermão, de fontes e autoridades doutrinárias diversas, sobretudo as definições do undécimo Concílio de Toledo (675) e a terceira parte da Suma de Santo Tomás. Mais uma vez, São Vicente demonstra sua prodigiosidade em abordar temas de ordem teológica elevada e abstrata por meio de ricas e didáticas analogias, tendo por objetos e contextos referências habituais e compreensíveis ao público. 


\section{Gustavo Cambraia Franco. O 'Espelho dos Santos': analogias da Virgem Maria nos sermões de São Vicente Ferrer (1350-1419)}

Algumas analogias e metáforas são, por vezes, mais complexas, sem que, no entanto, percam algo da mesma pulcritude. Esse é o caso da relação feita entre a maternidade de Maria e o cristal cromado, cuja complexidade e beleza refletem a imaginação e sensibilidade estética prodigiosa de São Vicente Ferrer. A primeira matéria, que introduz o leitor ao conjunto completo da analogia trata-se do mistério da unidade e trindade divina, considerada o princípio fecundador da maternidade de Maria.

Quomodo est possibile cum Pater, Filius et Spiritus Sanctus sint unum in essentia indivisibili, quod Filius assumpsit Humanitatem et factus sit Homo, cum sint uma entitas? Declaretur per similitudinem de sole uno, in quo potest considerari Pater generans, scilicet substantia; et Filius genitus, scilicet radius; et Spiritus spiratus, scilicet calor; et tamen no est nisi unus sol. Et transeunte radio per fenestram vitream, rubeam, vel alterius coloris, radius recipit illum colorem et non substantia solis nec calor. Sic, fenestra clarior crystallo erat Virgo Maria. Ideo cantat Ecclesia: Caeli fenestra facta est, et per eam transivit radius Solis aeterni, Filius Dei, intrans. Ad illuminandum domum huius mundi sine fenestra fractione. Imo clarior remansit. Et quando Angelus dixit sibi, Paries Filium, Virgo intellexit quod esset mater non Patris, nec Spiritus Sancti, sed Filii (Sancti Vicentii Ferrarii 1695: 216).

A analogia entre a Santíssima Trindade com o sol se expande para encontrar-se com a imagem da Virgem, de modo que o ciclo do mistério da Encarnação seja completado no esquema da metáfora. Os elementos do sol penetram pelo vitral de uma janela, mas somente o raio do sol, e não a sua substância ou calor, recebe a sua cor. O cristal cromado é a Virgem Maria. Todas os elementos do sol, ou seja, todas as Pessoas da Trindade atuam sobre o cristal ou sobre o corpo de Maria. O calor, o Espírito Santo, atua diretamente, em uma intervenção ativa e de apropriação sobre o cristal, mas o único que recebe algo dele, a sua cor, é o raio, pois somente Cristo recebeu de Maria sua carne e assumiu a natureza humana. O verso de um canto tradicional da Igreja, «o céu penetra pela janela», citado por São Vicente Ferrer, ilustra a conclusão do mistério e da analogia. Pelo corpo de Maria, o cristal cromado do vitral, penetra o Sol eterno, Cristo, a segunda Pessoa da Santíssima Trindade, que ilumina a habitação deste mundo sem fraturar o vitral. A luz do raio que penetra o cristal do vitral não somente recebe dele a cor, mas também o embeleza e o aperfeiçoa. Da mesma forma, Maria, ao receber em seu ventre o corpo de Cristo, tornouse sobrenaturalmente perfeita e embelezada pela graça da natureza divina que trazia em seu seio. À sua maternidade física, biológica e natural acrescenta-se uma perfeição sobrenatural e divina, que eleva ainda mais a condição de sua natureza humana. ${ }^{16}$

Um conjunto variado de apologias, analogias e exemplos relativos à pessoa de Maria encontramse dispersos em diversos sermões, sobretudo aqueles consagrados liturgicamente a alguma festa dedicada à Virgem. Salientamos uma breve série de metáforas, doutrinas e tipologias bíblicas que

16 Conforme Sauras (1972: 20-21), esse detalhe enriquece ainda mais o entendimento da analogia e o conceito da maternidade divina apresentado por São Vicente Ferrer. As analogias da esclavina do peregrino, do velo de lã, e do cristal cromado foram apresentadas por Sauras no texto citado. Julgamos oportuno retomá-las, pelo valor literário, teológico e estético que comportam. Acrescentamos, porém, uma série de conteúdos presentes nas fontes que foram omitidos pelo autor.

SCRIPTA, Revista internacional de literatura i cultura medieval i moderna, núm. 10 / desembre 2017 / pp. 26-48 ISSN: 2340 - 4841 doi:10.7203/SCRIPTA.10.11073 


\section{Gustavo Cambraia Franco. O 'Espelho dos Santos': analogias da Virgem Maria nos sermões de São Vicente Ferrer (1350-1419)}

tratam de suas virtudes. Maria é exaltada por São Vicente Ferrer como a única Rainha do céu e da terra, criatura acima de todas as criaturas. Ela é a Rainha dos Anjos (Regina Angelorum), por ter recebido em sua casa o mensageiro de Deus e ter sido digna de acolher em seu ventre virginal o Verbo divino, por cujo mistério canta a Igreja (In Hym. Natal. Dom.): Domus pudici pectoris templum repete sit Dei: intacta nescies virum, verbo concepit Filium (Sancti Vicentii Ferrarii 1695: 397).

$\mathrm{Na}$ ordem da hierarquia celeste e dos diversos graus daqueles que cantam eternamente louvores a Deus, a Virgem Maria encontra-se no grau máximo e superior das esferas celestes, seguida pelos Anjos, pelos Patriarcas, pelos Apóstolos e demais santos. Como prefiguração da posição da Virgem Maria na hierarquia celeste, canta o Salmo: «Laudate Dominum in sanctis eius, laudate eum in firmamento virtutis eius (Sl 150: 1-2). Maria é o firmamento das virtudes de Deus, pois ao ser confirmada e santificada por Deus, antes de seu nascimento era santa, como diz São Vicente (1695: 475). Ela é a imagem da vinha que frutifica em odores suaves e cujas flores são de honra e honestidade, profetizada e poetizada em Eclesiástico: Ego quase vitis fructificavi suavitatem odoris et flores mei fructus honoris et honestitatis (Eclo 24: 23). Ela é a coluna e a firmeza das virtudes e da verdade (I Tm 3: 15), o tabernáculo santificado (S/ 45: 3) de que fala as Escrituras, pois em seu interior habitou o próprio Deus. Para esclarecer o mistério do caráter esponsal e conjugal entre Deus entre Maria, criatura eleita e escolhida, e a amplitude da humildade divina ao se encarnar, Ferrer utiliza o sistema de classificação da escala dos seres da tradição platônica-agostiniana, que hierarquizava as criaturas, tanto angélicas (espirituais e incorpóreas, compostas pelos nove coros de Anjos), quanto as criaturas corpóreas: o céu empireo ou primeiro móvel (segundo outros filósofos), o céu cristalino, o firmamento, o fogo, o ar, a água, a terra, as criaturas elementares sensitivas (animais e aves), as criaturas elementares viventes não sensitivas (como as árvores e plantas), as criaturas elementares sem vida (as pedras). O homem, por ser composto de alma racional e corpo, é inferior em grau às criaturas espirituais, em relação à alma, e às criaturas corporais quanto ao corpo, pois fora formado a partir do limo da terra e não de outra matéria superior, como a matéria do céu. Portanto Deus, superior em grau a todas as criaturas espirituais e corporais quis se humilhar ( Fl 2: 6-7 e Hb 2:16) e não recebeu para Si uma criatura espiritual ou uma matéria corporal em grau superior, mas menor em seu último grau. O exempla ou similitude usado é sugestivo e evoca mais uma vez, como em outros sermões, o tema das bodas entre o rei (ou os filhos do rei) com súditos plebeus.

\footnotetext{
Modo, ut melius intelligatis, dicatur similitudo sive exemplum de rege volente contrahere cum filia rustici et pastoris, ut exaltaret illud genus. ( $\mathrm{O}$ quanta humilitas!) cum tamen posset cum filiabus regum contrahere. Ita fecit Christus: Noluit enim recipere creaturam spiritualem, nec corporalem in altiori gradu; sed voluit ducere filiam rustici ad se, ut eam faceret reginam in Paradiso et exaltaret super omnes creaturas. Sponsalia huius Matrimonii facta fuerunt in camera sive palatio uteri Virginalis (Sancti Vicentii Ferrarii 1694: 395).
}

A exegese das palavras sálmicas, que simbolizam referências nupciais, permite uma formosa associação analógica entre as virtudes de Maria com as qualidades do sol. In solis posuit tabernaculum suum et ipse tamquam sponsus procedens de thalamo suo (S118: 6). Diz Ferrer (1694: 395) que Maria é o sol- 


\section{Gustavo Cambraia Franco. O 'Espelho dos Santos': analogias da Virgem Maria nos sermões de São Vicente Ferrer (1350-1419)}

tabernáculo do qual sai Deus como esposo de seu leito conjugal. Assim como de todas as criaturas visíveis, o sol é o ser mais belo, mais elevado, mais claro e mais virtuoso, também a Virgem, entre todos os santos e santas, é a mais bela em santidade, a mais elevada em dignidade, a mais clara em bondade e a mais virtuosa em benevolência. Tal como o sol nasce pela manhã, claro e belo, sem corrupção, Maria deu à luz o Filho de Deus sem que sua virgindade fosse lesada.

A concepção da Virgem, por sua vez, deve ser entendida de maneiras distintas, seja do ponto de vista metafísico, histórico ou humano. Sua existência foi, antes de tudo, concebida na mente, no coração e no intelecto de Deus. Da mesma forma, os anjos, os primeiros seres a terem cognição direta dos atos de Deus, se alegraram e festejaram a revelação de seu nascimento e o fato de que ela seria a futura mãe do Salvador. Causava aos anjos tristeza o fato de que a cidade celeste estivesse despopulada pela queda dos anjos e pelo pecado dos homens, mas alegravam-se por saberem que o céu haveria mais uma vez de estar cheio após o Redentor abrir-lhes as portas. Do ponto de vista da história humana, Maria é uma pessoa cuja natureza pura e imaculada representa a reparação dos atos pecaminosos de Adão e Eva, que haviam causado a perdição e condenação de todo o gênero humano. O primeiro casal cogitava com enorme dor e tristeza o fato de que seu defeito e culpa creditavam débito eterno a todos os habitantes da cidade terrena, grandes ou pequenos, que com eles deveriam também ser excluído da fruição de Deus e do Paraíso e, como filhos de sua semente, ser vítimas de dores, misérias e calamidades. Se Eva havia sido expulsa do Paraíso terrestre e trazido a morte corporal aos homens, Maria, pelo contrário, haveria de abrir as portas do Paraíso celeste e trazer ao homem a vida da alma (Sancti Vicentii Ferrarii 1695: 23-24).

A tipologia do caráter adâmico de Cristo e de Maria como imagem invertida de Eva é um tema que, em primeiro lugar, está explicitado na Biblia, nas palavras de São Paulo: «Pois, do mesmo modo que em Adão todos morrem, assim também todos reviverão em Cristo.» (1 Cor 15: 22). O mesmo tema será tratado em diversas ocasiões durante os séculos medievais, com base nos ensinamentos propostos pelos Padres antigos. Santo Agostinho explicita esta analogia, ao explicar a virgindade intacta de Maria em um sermão do século V, que diz: Maria unde? Ex Adam. Adam unde? De terra. Si Adam de terra, et Maria de Adam, ergo et Maria terra. Si Maria terra, agnoscamus quod cantamus: veritas de terra orta est (San Agustín 1983: 25). Por meio de uma analogia entre a fecundidade da terra e o ventre de Maria, Agostinho diz que Maria procede de Adão e Adão da terra. Maria procede, portanto, da terra e é ela mesma a terra na qual nasce Cristo. Cristo possui, portanto, a mesma origem do primeiro homem, mas como o Novo Adão, deveria nascer de uma terra pura e virgem, isto é, do ventre de Maria, de forma que se cumprisse o que diz a Escritura: «A verdade brotou da terra.» (S/ 84: 10). Pela analogia de proporcionalidade, Cristo está para Adão, assim como Maria está para Eva e, da mesma forma, por inversão analógica, a expulsão dos primeiros pais prefigura a Anunciação do arcanjo à Virgem (Franco Júnior 2013: 18).

As circunstâncias da Anunciação, relatadas no primeiro capítulo do Evangelho de Lucas, permitem um aprofundamento ainda maior das analogias entre Eva e Maria no esquema de São Vicente 
Ferrer. Eva é o início e a causa de todos os males, como Maria é a causa e início de todo o bem. A mulher que é a causa do mal fora desposada, assim Deus quis nascer de uma mulher virgem e desposada. Eva fora incitada e visitada por um anjo mal, Lúcifer, na forma de uma serpente, mas Maria foi saudada por um anjo bom. A primeira foi tentada, enganada e seduzida, a segunda não foi tentada, mas informada pelo anjo, ao dizer: «O Espírito Santo virá sobre ti.» (Lc 1: 35). Eva consentiu às palavras do diabo, Maria inclinou-se e consentiu às palavras do anjo. Eva colheu e comeu do fruto proibido e colocou-o em seu ventre, o qual foi causa de morte. Maria concebeu um fruto que foi a causa da vida. Pela primeira mulher, toda a natureza prosterna em dor e miséria, e as portas do Paraíso foram fechadas. Pela Virgem Maria a natureza é reparada e as portas do Paraíso dilatadas e abertas (Sancti Vicentii Ferrarii 1695: 21-22).

Entre os temas marianos apresentadas por Ferrer, o da Imaculada Conceição ocupa um lugar de destaque. Os sermões apresentam uma série de elucubrações metafísicas acerca da concepção e do nascimento de Maria e do lugar privilegiado e providencial que ela ocupa na história da salvação. Diante desse amplo quadro de providencialismo divino e histórico, São Vicente Ferrer é incisivo no tange à matéria da concepşão imaculada de Maria, isto é, de sua santificação no primeiro instante de sua existência humana. Segundo o santo, Maria foi santificada no dia e na hora em que sua alma foi criada e infundida no seu corpo. Foi santificada no útero de Ana, sua mãe, não quando devia nascer, nem no último dia, semana ou mês de sua gestação, mas na mesma hora em que se formou seu corpo e sua alma criada. Para São Vicente, Maria recebeu a graça não em partes, como as outras criaturas, mas em sua plenitude, em concordância com as palavras que São Vicente atribui a São Bernardo, mas que, na verdade, são de São Jerônimo ${ }^{17}$ (c. 347-420): Caeteris perpartes gratia praestatur; Mariae autem tota se infundit plenitudo gratiarum (1695: 28). Baseado em uma interpretação alegórica do livro de Gênesis, São Vicente Ferrer retoma simbolicamente a passagem da criação da luz, do Fiat Lux, para descrever a concepşão imaculada da Virgem:

\footnotetext{
Lux dicitur, illa benedicta generatio Virginis Mariae, quia sine tenebrae culpae facta est. [...] Et facta est lux. Ecce sanctificatio Virginis Mariae. Non credatis quod fuerit sicut in nobis qui in peccatis concipimur, et nascimur et nutrimur [...] sed statim postquam corpus fuit formatum et anima creata, tunc fuit sanctificata (Sancti Vicentii Ferrarii 1695: 433-434).
}

A concepção e a geração de Maria são realidades não apenas no plano carnal e terreno, mas é a completude de uma prefiguração profética que ressoa na revelação bíblica e que se espelha analogicamente no plano da ordem natural e da criação divina. A exegese figural e alegórica das Escrituras conduz o autor a explorar o livro do Gênesis de tal modo a encontrar, em seus primeiros versículos, que tratam da criação do mundo, o esquema temático da festividade litúrgica do Nascimento da Virgem, bem como uma correspondência e personificação de Maria nas palavras bíblicas. Desse modo, o sermonista colhe por tema o texto de Eclesiástico: Memoria mea in generationes saeculorum (Eclo 24: 28). A memória de Maria é o seu nascimento que, ecoando desde o início

17 O texto encontra-se no sermão sobre a Assunsão de Maria (Hieronymus ad Paulam et Eustochium de assumptione sanctae Mariae), conforme nota da presente edição. 
e geração dos séculos, durará para sempre. Para fundamentar seu tema, Ferrer procede a uma exegese intrincada dos versículos iniciais da Bíblia: In principio creavit Deus caelum et terram (Gn 1:1). O sermão apresenta uma aclaração filosófica e teológica do significado do termo século (saeculum), de modo a desenvolver uma exegese propriamente mariana da passagem bíblica do tema do sermão. São Vicente diferencia os dois séculos existentes, o Céu Empíreo do qual falou Estrabão (Lib. I, Cap. I, Genes.), e o qual, tão logo fora criado, se tornou repleto de criaturas angélicas espirituais e incorruptíveis, e a Terra, o século presente das criaturas corporais e corruptíveis.

A criação dos dois séculos pode-se se dizer geração (generatio), pois a geração de qualquer criatura é o seu princípio, segundo a definição de Aristóteles: Generatio est progressio de non esse ad esse (Lib. I de Generat. Cap. 4). Os dois séculos, portanto, Céu e Terra, tiveram seu princípio pela criação, e tendo ambos o princípio do ser, podem ser considerados gerados. A memória, pois, ou a natividade de Maria, dura retroativa e futuramente por todas as gerações, passadas e futuras. Os dois planos de criação e geração, o Céu e a Terra, são figuras simultâneas da conjunção matrimonial dos pais de Maria, Joaquim e Ana. Joaquim é figurado pelo Céu, pois toda a sua vida foi celestial e nobre, e pode ele dizer: Nostra conversatio in caeli (Phil 3: 20). Por analogia, a Terra é a imagem de Ana, pois assim como a terra produz os seus frutos segundo a influência que recebe do Céu, também a mulher concebe seus frutos segundo a influência do homem. A analogia bíblica se completa pelas palavras do Salmo: Benedixisti Domine terram tuam [...] Dominus dabit benignitatem et terram nostram dabit fructum suum (Sl 84: 2 e 13). A terra, antes estéril e vazia (Gn 1:2) é Ana, que pela benignidade divina e para a utilidade do homem, concebeu Maria, seu fruto (Sancti Vicentii Ferrarii 1695: 430).

Da mesma forma que na passagem acima, na qual Maria aparece como uma nova criação prefigurada na narrativa da criação original do Gênesis, tipologias bíblicas relativas à figura de Maria permeiam todos os sermões vicentinos que tratam da Virgem. Elas expressam o modo com que a piedade mariana do pregador é vertida para o contexto geral da exegese bíblica, na qual eventos, coisas e personagens do Antigo Testamento não prenunciam apenas a figura central de Cristo e dos sacramentos, mas apontam, também, para a pessoa e as virtudes de Maria. Nesse caso, o autor atribui à pessoa de Maria o conjunto de figuras e imagens femininas descritas na Bíblia, sobretudos dos livros sapienciais e poéticos, como Provérbios, Sabedoria, Eclesiástico e do Cântico dos Cânticos.

O sermão sobre a concepção imaculada de Maria, por exemplo, tem como tema a sugestiva passagem de Provérbios: «Quando os abismos não existiam, eu fui gerada.» ( $\operatorname{Pr} 8$ : 24). São Vicente relaciona, assim, o imaculismo com a noção de pré-criação, uma vez que a Virgem, a tota pulchram descrita em Cânticos, fora primeiro concebida na mente divina antes que tudo existisse (Ct 4 : 7). A passagem é o tema de um velho canto católico do século IV. É uma das cinco antífonas para os salmos da Véspera para a Festa da Imaculada Conceição. Seu texto mescla a passagem de Cânticos com textos do livro de Judite: Tota pulchra es, Maria. Et macula originalis non est in Te. Tu gloria Ierusalem. Tu laetitia Israel. Tu honorificentia populi nostri. Tu advocata peccatorum. O Maria, O Maria. 
Gustavo Cambraia Franco. O 'Espelho dos Santos': analogias da Virgem Maria nos sermões de São Vicente Ferrer (1350-1419)

Virgo prudentissima. Mater clementissima. Ora pro nobis. Intercede pro nobis. Ad Dominum Iesum Christum. A mesma ideia da mítica figura feminina e sapiencial relacionada à pré-criação e da esposa pura de Cânticos e sua identificação com a Virgem Maria encontram-se em várias obras poéticas e do cancioneiro popular hispânico tardo-medieval (Twomey 2008: 185 ss), numa abordagem que faz eco às famosas interpretações marianas de Bernardo de Claraval.

As razões tipológicas da hermenêutica de Vicente Ferrer estão fundamentadas na visão especular e analógica entre a natureza da mulher e do livro. As Sagradas Escrituras, maximamente o Antigo Testamento, é toda ela "grávida" de mistérios celestes. Assim como uma mulher carrega o filho em seu útero, também pode-se dizer que as Escrituras concebem e geram em seu interior inexauríveis mistérios e segredos divinos. São Vicente Ferrer retoma, nesse sentido, a mesma analogia das Escrituras como a mulher grávida de revelações celestes que aparece em uma homilia de Beda, o Venerável (c. 672-735), em cuja introdução se lê: Sanctam venerandamque praesentis festi memoriam, paucis quidem verbis Evangelista comprehendit, sed non pauca coelestis mysterii virtute gravidam reliquit(Bedae Venerabilis 1843: 156).

Segundo nosso pregador, que se baseia no conceito de concepşão escriptural, o mistério da Virgem Maria aparece em todos os livros das Sagradas Escrituras e em todos os seus Cânticos. Em cada versículo, direta ou indiretamente está ela misticamente contida. Qual não é a honra e graça da Virgem, pergunta São Vicente Ferrer, uma vez que se encontra figurada em todos os livros e capítulos das Escrituras? Assim se deve entender, por exemplo, o episódio em que Moisés, enquanto apascentava o rebanho no monte santo do Sinai, teve a visão da sarça ardente (Ex 3: 1-2). O Monte Sinai é a vida da Virgem Maria. A sarça que ardia no fogo e não se consumia é a pessoa da Virgem. O fogo que não consumia a sarça, e nem suas flores e folhas é o Filho de Deus Incarnado sem corrupção. Da mesma concepção divina e da figura de Maria diz o Eclesiástico: «Estendi meus galhos como um terebinto, meus ramos são de honra e graça.» (Eclo 24: 22). A Virgem Maria concebida na Sagrada Escritura estende seus galhos, isto é, todos os seus livros, e seus ramos menores, que são seus capítulos. Daqui o sentido próprio do tema escolhido: «Quando os abismos não existiam», isto é o Novo Testamento, «eu fui gerada», isto é, concebida no Antigo Testamento (Sancti Vicentii Ferrarii 1695: 24-25).

A mesma metáfora entre o livro e a Virgem encontra-se formulada em um outro sermão de maneira ainda mais nítida. O Verbo de Deus Pai, diz São Vicente Ferrer, foi escrito em um pergaminho virgem, isto é, no ventre de Maria, o que se entende pelas palavras da Escritura: Verbum caro factum est (Jo 1: 14). A analogia da Virgem como um livro no qual Deus escreve a sua Palavra eterna fora profetizada por Isaías: Dixit Dominus ad me: Sume tibi librum grandem, et scribe in eo (Is 8: 1). O livro grande é a Virgem Maria, maior que o céu e a terra, no qual o Verbo Eterno escrito por Deus Pai assumiu sua humanidade, conforme as palavras de uma homilia de São Bernardo (De Laud. B. V. Mariae. Homilia IV) citadas por São Vicente Ferrer (1693: 607): O venter capacitor caelo, quia quem caeli capere non poterant tuo gremio contulisti.

SCRIPTA, Revista internacional de literatura i cultura medieval i moderna, núm. 10 / desembre 2017 / pp. 26-48 ISSN: 2340 - 4841 doi:10.7203/SCRIPTA.10.11073 
Ao longo do sermão sobre a imaculada conceição de Maria, Ferrer segue a colher dos livros sapienciais referências à imagem feminina da sabedoria, interpretadas como antecipação profética do nascimento e maternidade divina da Virgem Maria, como faz com a passagem de Provérbios: Dominus possedit me in initium viarum suarum, antequam quidquam faceret a principio: ab aeterno ordinata sum et ex antiquis antequam terram fieret $(\operatorname{Pr} 8: 22)$. Na sua vontade imutável, antes de todas as suas criaturas, Deus concebe a Virgem no princípio, isto é, em seu logos, na sua inteligência e razão. Maria é anunciada, ainda, em Eclesiástico: Ego in Altissimis habitavi et thronus meus in columna nubis (Eclo 24: 4-7). O texto sagrado anuncia profeticamente o reinado da Virgem. Maria habita no mais alto dos céus, acima de todos as criaturas, anjos e homens, e tem seu trono sobre as nuvens, como Rainha do Céu. Ela é a mulher forte e virtuosa profetizada pelo rei Salomão: Mulierem fortem, quis invenient? Procul et de ultimis finibus praetium eius (Pr 31: 10). Ela é a alegria da Cidade de Deus e dos anjos. Santificada pelo rio do Espírito Santo no instante de sua concepção, ela é o próprio tabernáculo onde o Altíssimo repousa: Fluminis impetus laetificat civitatem Dei: sanctificavit tabernaculum suum Altissimus (Sl 45: 5).

Assim como Moisés ornava o tabernáculo no deserto com panos e linhos, assim Deus ornou a Virgem Maria com todas as virtudes e com sua glória, por carregar no ventre seu corpo divino. São Vicente (1695: 24 e 27) compara a concepção de Maria à construção e consagração de uma Igreja. Uma vez construída a Igreja, deve entrar o bispo e consagrá-la. Assim com a Virgem Maria, após ter seu corpo formado e a alma infusa, veio o Bispo, o Espírito Santo, e a consagrou, isto é, a santificou, conforme prenunciado na imagem da nuvem de glória que cobria o tabernáculo mosaico, descrita em Êxodo: Postquam omnia perfecta sunt, operuit nubes tabernaculum testimonii et gloria Domini implevit illud (Ex 40: 32).

De acordo com o mesmo princípio da tipologia bíblica e da interpretação alegórica da história sagrada, a pessoa de Maria se acha prefigurada, também, em personagens do Antigo Testamento, como é o caso citado da pessoa da virgem Rebeca, mulher de Isaac e mãe dos irmãos Esaú e Jacó. Ao servir da água da fonte ao servo enviado por Abraão, o qual procurava uma esposa para seu filho Isaac, Rebeca, que segundo o texto de Gênesis (24: 16), «era uma jovem agradável de se ver e uma virgem belíssima», escutou do servo as seguintes palavras: «Esta é a virgem que o Senhor preparou para o filho de meu senhor.» (Gn 24: 44). Diz São Vicente Ferrer (1693: 318), o mistério significado no texto é que Abraão, que enviou seu procurador Eliezer para anunciar à Rebeca seu propósito, representa a figura de Deus Pai, que enviou seu procurador, o Arcanjo Gabriel, para anunciar à Maria, uma virgem que, como Rebeca, era muito bela e formosa, o mistério de sua gravidez divina, conforme profetizado por Isaías: «Eis que uma Virgem conceberá e dará luz a um filho.» (Is 7: 14). E assim como Rebeca deu abundantemente de beber ao procurador da água da fonte com um cântaro, Deus distribuiu ao mundo, através de Maria, abundantes graças e dons espirituais. 


\section{Gustavo Cambraia Franco. O 'Espelho dos Santos’: analogias da Virgem Maria nos sermões de São Vicente Ferrer (1350-1419)}

\section{Conclusão}

A exposição do autor sobre as virtudes de Maria seguiu o avanço gradual que o desenvolvimento das doutrinas marianas experimentou ao longo da Idade Média, até que estas se consolidassem, do século XIV em diante, mediante tratados teológicos, disposições eclesiásticas, conciliares e normativas relativas às diversas festividades e cultos marianos. Estas tenderam a se difundir pela Europa de forma cada vez mais rápida, tanto no plano da alta cultura e das práticas da Igreja oficial, quanto nas manifestações de devoção popular. Tanto os sermões consagrados especialmente à Virgem Maria, quanto os diversos trechos marianos que permeiam outros sermões -como, por exemplo, os sensíveis e comoventes relatos extra-evangélicos dos diálogos entre Maria e Jesus durante episódios marcantes, como na véspera da Santa Ceia e durante sua crucifixão- são construídos sobre sólidas argumentações, que mesclam de maneira indistinta, alegorias e tipologias bíblicas com conteúdos de opúsculos exegéticos e homilias de mestres contemporâneos e patrísticos. Entre as referências mais usadas, destacam-se obras e citações de autores que mais marcadamente dedicaram-se a apologias à Virgem Maria e que mais contribuíram para a difusão de seu culto no medievo ocidental, como Beda, o Venerávele São Bernardo de Claraval. Os sermões sobre Maria são envolvidos, também, por relatos da tradição católica e por meditações por vezes tomadas dos Apócrifos -como é caso, por exemplo, das meditações e histórias sobre a o tempo de exílio da Sagrada Família no Egito- obras de história eclesiástica, cânticos sacros, hinos marianos e orações de ofícios litúrgicos.

As bases teóricas e conceituais que sustentam as argumentações são retiradas pelo pregador do contexto filosófico clássico, patrístico e escolástico. No entanto, em que pese na exposição vicentina o caráter rigorosamente escolástico e doutrinário dos temas, é na vertente do pensamento analógico e especular, como vimos, que entendemos melhor a ligação espiritual e devocional do santo para com a figura da Virgem, e o modo imagético e sensorial com que transmite uma série de conhecimentos primariamente especulativos e abstratos, sobretudo nas constantes tipologias, nas alegorias e metáforas bíblicas, bem como nos inúmeros exemplos espirituais e morais acerca da história, da natureza e das virtudes de Maria. 


\section{Gustavo Cambraia Franco. O 'Espelho dos Santos’: analogias da Virgem Maria nos sermões de São Vicente Ferrer (1350-1419)}

\section{Bibliografia}

\section{Fontes primárias}

Bedae Venerabilis. (1843) «Homilia XXII», em The Miscellaneous Works of Venerable Bede (trans. by J. A. Giles), vol. V. London, Whittaker and Co.

BÍBLIA DE JERUS ALÉM. São Paulo: Paulus, 2002.

BÍBLIA SAGRADA. Novo Testamento (trad. de Pe. Matos Soares). Porto: Tip. Sociedade de Papelaria, 1956.

Hugo de São Vítor. (2001) Didascálicon. Da Arte de Ler (trad. de A. Marchionni). Petrópolis, Vozes. (1879) «De Scripturis et Scriptoribus Sacris», em MIGNE, J. -P. (ed.) Patrologiae cursus completus: series latina. Paris, Migne, v. 175, c. 09-28.

Jacopo de Varazze. (2003) Legenda Aurea. Vidas de Santos (trad. de H. Franco Júnior). São Paulo, Companhia das Letras.

S. Augustinus. (1841) «Speculum de Scriptura sacra. Praefatio», em Migne, J. -P. (ed.) Patrologiae cursus completus: series latina. Paris, Migne, v. 34, c. 889.

Sancti Vicentii Ferrarii. (1693) «Dominica I Post Octava Epiphaniam», em Rocabertí, Thomas de (ed.) Opera Omnia, tomi primi, pars prima. Valentiae, Iacobi de Bordázar y Artazù, pp. 314-320.

(1693) «Sabbato. Post Dominicam III. Quadragesima. Sermo unicus», em Rocabertí, Thomas de (ed.) Opera Omnia, tomi primi, pars secunda. Valentiae, Iacobi de Bordázar y Artazù, pp. 606-613.

(1695) «In Festo Assumptionis Beatissimae Virginis Mariae. Sermo II. Ex Evangelio», em Rocabertí, Thomas de (ed.) Opera Omnia, tomus tertius. Valentiae, Iacobi de Bordázar y Artazù, pp. 389-395.

(1695) «In Festo Conceptionis B. Virginis Mariae. Sermo unicus», em Rocabertí, Thomas de (ed.) Opera Omnia, tomus tertius. Valentiae, Iacobi de Bordázar y Artazù, pp. 10-28.

(1695) «In Festo Nativitatis B. Virginis Mariae. Sermo II», em Rocabertí, Thomas de (ed.) Opera Omnia, tomus tertius. Valentiae, Iacobi de Bordázar y Artazù, pp. 429-437.

(1695) «In Festo Omnium Sanctorum. Sermo I», em Rocabertí, Thomas de (ed.) Opera Omnia, tomus tertius. Valentiae, Iacobi de Bordázar y Artazù, pp. 473-480. 
Gustavo Cambraia Franco. O 'Espelho dos Santos': analogias da Virgem Maria nos sermões de São Vicente Ferrer (1350-1419)

\section{Obras modernas}

Ávila, S. M. (2016) «Culto y servicio amoroso a la Virgen en la Literatura medieval. El milagro del prometido de la Virgen y sus versiones hispánicas», em Revista de Lenguas y Literatura Catalana, Gallega y Vasca (RLLCGV), XXI, pp. 13-37.

Bedouelle, G. (1987) La fuerza de la palabra: Domingo de Guzmán. Salamanca, Editorial San Esteban.

Boaga, E. (1998) «Maria nell'itinerario della vita spirituale dal Medioevo al Rinascimento (sec. XIXV)», em Toniolo, E. M (ed.) La Madre del Signore dal Medioevo al Rinascimento. Roma, Centro de Cultura Mariana, pp. 176-203.

Bougerol, J. G. (1988) Introduzione a S. Bonaventura. Vicenza, LIEF.

Canettieri, P. (2001) Iacopone e la Poesia Religiosa nel Duecento. Milano, Biblioteca Universali Rizzoli.

Comte, A.-P. (1877) Vie de saint Amédée, évêque de Lausanne, né à Chatte en 1110. Grenoble, Baratier et Dardelet.

Correa, J. M.. (1979) A Analogia da Fé na Interpretação da Sagrada Escritura Segundo Santo Tomás de Aquino. Extrato de tese doutoral apresentada na Faculdade de Teologia da Universidade de Navarra, Braga.

Corvino, F. (2006) Bonaventura da Bagnoregio, francescano e pensatore. Roma, Città Nuova.

Costa, Ricardo da. (2009) «A Ciência no Pensamento Especulativo Medieval», Sinais 5, vol. 1, setembro, pp. 132-144. [http://www.ricardocosta.com/artigo/ciencia-no-pensamentoespeculativo-medieval] (20/02/2016, data da última consulta).

(2010) «O que é Deus? Considerações sobre os atributos divinos no tratado Da Consideração (1149-1152), de São Bernardo de Claraval», Revista Coletânea. Revista de Filosofia e Teologia da Faculdade de São Bento do Rio de Janeiro. Rio de Janeiro, Editora Lumen Christi, Ano IX, fasc. 18, jul-dez, pp. 223-238. [http://www.ricardocosta.com/artigo/o-que-e-deus-consideracoessobre-os-atributos-divinos-no-tratado-da-consideracao-1149-1152-de] (13/05/2016, data da última consulta).

(2011) «O verdadeiro amor nasce de um coração puro, de uma consciência boa e de uma fé sincera, e ama o bem do próximo como se fosse seu. A mística de São Bernardo de Claraval», em Costa, M. R. N. (org.) Perspectiva Filosófica. Recife, vol. 1, n. 35, jan-jun, pp. 125-140. [http://www. ricardocosta.com/artigo/o-verdadeiro-amor-nasce-de-um-coracao-puro-de-uma-conscienciaboa-e-de-uma-fe-sincera-e-ama-o] (13/05/2016, data da última consulta).

Daniel-Rops, H. (1993) A Igreja das Catedrais e das Cruzadas. São Paulo, Quadrante.

De Lubac, H. (2002) Medieval Exegesis: The Four Senses of Scripture, vol. 2. Grand Rapids, MI, Eerdmans.

Esponera Cerdán, A. (2006) El oficio de predicar. Los postulados teológicos de los sermones de San Vicente Ferrer. Salamanca, Ed. San Esteban.

SCRIPTA, Revista internacional de literatura i cultura medieval i moderna, núm. 10 / desembre 2017 / pp. 26-48 ISSN: 2340 - 4841 doi:10.7203/SCRIPTA.10.11073 
Gustavo Cambraia Franco. O 'Espelho dos Santos': analogias da Virgem Maria nos sermões de São Vicente Ferrer (1350-1419)

Franco Júnior, H. (2013) «Similibus simile cognoscitur. O pensamento analógico medieval», Medievalist, $\mathrm{n}^{\circ} 14$, pp. 1-37. [http://medievalista.revues.org/344] (27/01/2016, data da última consulta).

Hamesse, J. (2004) «El Modelo Escolástico de la Lectura», em Cavallo, G. / Chartier, R. (org.) Historia de la Lectura en el Mundo Occidental. Madrid, Taurusminor, pp. 179-210.

Jedin, H. (1986) Manual de Historia de la Iglesia, tomo IV. Barcelona, Herder.

Maggioni, C. (1998) «Culto e pietà mariana nel medioevo (secoli XI-XVI)», em Toniolo, E. M. (ed.) La Madre del Signore dal Medioevo al Rinascimento. Roma, Centro de Cultura Mariana, pp. 81-129.

Martines Peres, V. (2012) «Aspectos de la poliédrica influencia de los clásicos. Nuevas imágenes clave de la influencia de san Vicente Ferrer en Italia», eHumanista, vol. 22, pp. 582-597. [http:// rua.ua.es/dspace/bitstream/10045/34299/1/2012_Martines_eHumanista.pdf] (22/02/2015, data da última consulta).

Martínez Romero, T. (1992) «Introducció» a Ferrer, V. Els sermons de sant Vicent Ferrer. València, Tres i Quatre, pp. 9-46.

(1992) Aproximació als sermons de sant Vicent Ferrer. València, Denes.

(1993) «Sant Vicent Ferrer: religiós, predicador i polític», em Sermons. Estudi introductori i edició de Tomàs Martínez. Romero. València, Eliseu Climent/3i4, 1993.

Nuet Blanch, M. (2000-2001) «El salvamento de náufragos, metáfora de la penitencia en el gótico catalán», LOCUS AMOENUS, 5, pp. 53-65.

Perarnau i Espelt, J. (1987) «Sobre l'eclesiologia de sant Vicent Ferrer. A propòsit del llibre de Ramón Arnau i García», Revista Catalana de Teología, XII, pp. 427-435.

(1999) «Cent anys d'estudis dedicats als sermons de sant Vicent Ferren», Arxiu de Textos Catalans Antics, no 18 (Dedicado a: Estudis i inventari de sermons de Sant Vicent Ferrer), pp. 09-62.

Robles Sierra O. P., A. / Esponera Cerdán O. P., A. Introducción a los Sermones. [http://biblioteca. campusdominicano.org/vitachristi.pdf] (12/11/2015, data da última consulta).

Rodrígues, E. S. (2014) Toledo y los Dominicos en la época medieval. Instituciones, economia, sociedad. Cuenca, Ediciones de la Universidad de Castilla-La Mancha.

Rougemont, D. de. (1988) O Amor e o Ocidente. Rio de Janeiro, Guanabara.

Rubio, J. E. (2007) «Philosophia Ancilla Theologiae. Sant Vicent, intel-lectual i predicador popular». Reedició del treball «Estratègies divulgatives i pedagogiques en els sermons vicentins de la filosofia a la moral», em Actes del I Simposi Internacional Vicentí celebrat a València el 26-29 d'abril de 2005 (El fuego y la Palabra. San Vicente en el 550 aniversario de su canonización). València, Generalitat Valenciana, pp. 133-144.

Salvador González, J. M. (2013) «Benedicta in mulieribus. La Virgen María como paradigma de la mujer en la tradición patrística y su posible reflejo en la pintura gótica española», em Salvador González, J. M. (org.) Mulier aut Femina. Idealidad o realidad de la mujer en la Edad Media, Mirabilia, 
Gustavo Cambraia Franco. O 'Espelho dos Santos': analogias da Virgem Maria nos sermões de São Vicente Ferrer (1350-1419)

no. 17, 2, pp. 11-51. [http://www.revistamirabilia.com/sites/default/files/pdfs/201302010. pdf] $(02 / 03 / 2016$, data da última consulta).

Sánchez Sánchez, M. A. (1999) Un Sermonario Castellano Medieval. Vol. I. Salamanca, Ediciones Universidad de Salamanca.

Sauras, E. (1972) «La Santísima Virgen en los sermones de san Vicente Ferrer», Teología Espiritual, Valencia, vol. XVI, no. 46, pp. 43-69. [http://www.almudi.org/articulos-antiguos/7260-lasantisima-virgen-en-los-sermones-de-san-vicente-ferrer-emilio-sauras] (25/02/2016, data da última consulta).

Schmitt, C. (1982) «Nicolas de Lyre», Dictionnaire de Spiritualité, XI, Paris, pp. 291-292.

Schmitt, F. S. (1988) «Anselm of Canterbury, St.», em Strayer, J. R. (ed.) Dictionary of the Middle Ages, vol. 1. New York, Charles Scribner's Sons, pp. 495-497.

Suitner, F. (1999) Iacopone da Todi. Poesia, mistica, rivolta nell'italia del medioevo. Roma, Donzelli.

Twomey, L. K. (2008) The Serpent and the Rose. The Immaculate Conception and Hispanic Poetry in the Late Medieval Period. Leiden / Boston, Brill.

Ysern i Lagarda, J.-A. (2003) «Sant Vicent Ferrer: Predicació i societat», Revista de Filología Románica, núm. 20, pp. 73-102.

SCRIPTA, Revista internacional de literatura i cultura medieval i moderna, núm. 10 / desembre 2017 / pp. 26-48 ISSN: 2340 - 4841 doi:10.7203/SCRIPTA.10.11073 